\title{
Study on Water Injection Formula by Grey Correlation Method for Offshore Water Flooding Reservoir
}

\author{
Junting Zhang*, Meinan Wang, Pingzhi Gong, \\ Zhicheng Yang, Xilin Liu \\ Bohai Oilfield Research Institute of CNOOC Ltd.-Tianjin Branch, Tianjin, China \\ Email: *zhangjt26@cnooc.com.cn
}

How to cite this paper: Zhang, J.T., Wang, M.N., Gong, P.Z., Yang, Z.C. and Liu, X.L. (2018) Study on Water Injection Formula by Grey Correlation Method for Offshore Water Flooding Reservoir. Journal of Geoscience and Environment Protection, 6, 1-11. https://doi.org/10.4236/gep.2018.68001

Received: June 30, 2018

Accepted: July 31, 2018

Published: August 3, 2018

Copyright (c) 2018 by authors and Scientific Research Publishing Inc. This work is licensed under the Creative Commons Attribution International License (CC BY 4.0).

http://creativecommons.org/licenses/by/4.0/

\section{(c) (†) Open Access}

\begin{abstract}
Based on the development of the offshore water drive reservoir, the determination of reasonable water injection of monolayer and single well affects the distribution of remaining oil and development effect of oil field water flooding, so this paper, using the grey correlation analysis method, studies the main factors influencing the dividing coefficient of water-injection and weight. This method takes into account the effective thickness, permeability, injection-production well spacing, the number of injection-production wells, and the direction of formation coefficient factors such as the influence of the dividing coefficient for injection. The formula for water-injection multi-factor controlled is established, at the same time, applying water injection formula of this article and the conventional on injection allocation of A-platform offshore injection wells. And the difference of single-well injection-allocation quantity in layers is analyzed. Based on a platform offshore, layers exist in the process of water flooding and the problems such as the contradiction between the layers, put forward the necessity of layered water injection through this article to determine water injection formula and injection allocation on a platform of injection wells by implementing effect which can be found. A platform for water flooding development of water cut under control, natural decline rate reduced to verify the reliability and practicability of the formula to determine injection in this paper. It has certain guiding significance to the offshore for the water-injection development oilfield.
\end{abstract}

\section{Keywords}

Grey Correlation, Weight, Separated Layer Water Injection, Influencing Factors, Water Injection Formula 


\section{Introduction}

At present, domestic water distribution methods are mainly divided into two types which are macro-distribution and micro-distribution. Macro-distribution method is based on the whole oil field or block as the research object, and is according to the development pattern of the oil field or block to get the water distribution of the oil field or block [1] [2]. Micro-distribution method is based on well group, the single well or layer segment as the research object, from the micro consideration cited correction coefficient to account the injection water quantity of single well or well group [3] [4]. Or using dividing coefficient to split with the shunt injection wells connected to all the production wells in the direction of the flow of liquid [5] [6]. Through the injection-production balance, the water injection of single water well is computed, or to split single water well of the water injection well to get layer segment distribution water [7] [8]. But study on injection is relatively less in abroad. And in United States J. L. Anthony et al., propose the method of displacement volume to distribute water injection, and determine the large well-group water flooding in research of water injection rate [9] [10]. In United States P. M. Jarern and others apply Hearn and Hall curve on the new conversion well study of water injection rate [11] [12]. The former Soviet Union P. M. caTTapBo has used statistical methods to study the effect of injection rate on fluid withdrawal rate [13]. In abroad most of these methods are the micro-injection methods.

These methods are mostly reflected badly in the specific formula for calculating the geological condition factor less and failed to make full use of existing monitoring data and production performance data and dividing coefficient of adaptability and practicality was worse. In this paper, we consider the geological conditions, the combination of dynamic and static data to determine the main factors of affecting the dividing coefficient and the weight of each factor [14], reasonable dividing coefficient of block is established, a reasonable stratified water injection formula of block injection wells is got, achieving rational distribution of single well of water injection well and increasing adjustment effect of water flooding.

\section{The Theory of Grey Correlation Analysis Method}

Grey correlation analysis method is a method of multivariate statistical analysis, by solving key relationships between various factors in the system, identifies important factors affecting target values, and so as to master the main features of things. It is a quantitative description of a system development trend and comparison methods [15] [16]. It is based on the sample data for each factor, by gray correlation degree to describe the strength, the size and order of the relationship between various factors. If the sample data series reflects that the changed trend (direction, size, speed, etc.) of two factors are basically the same, the correlation degree between them is larger; conversely, it is smaller. 
Deng julong put forward the grey system theory that has wide applications in areas such as oil and natural gas exploration and development [17] [18] [19]. Grey correlation analysis of grey system theory is a quantitative description and comparison of methods of dynamic development trends. The dividing coefficient is as a grey system in this method, based on the sample data of various factors, by the correlation degree to describe the relationship between factors associated with strength, size and order. It may depend on chaos and timing sequential of the system to search for the evolution law of the system in the case of less data, so as to better determine the main factors, providing a theoretical basis for prediction and control of system. Grey correlation analysis generally requires the following five steps.

\section{1) Determine the Sequence of Analysis}

On the basis of analysis of the target variable of the research questions, to determine a dependent variable and multiple independent variables factors. The dependent variable data constitute the reference sequence, variable data constitute the comparative sequence, is expressed respectively as formula (1).

$$
\begin{gathered}
\vec{y}_{0}=\left(y_{0}(1), y_{0}(2), \cdots, y_{0}(n)\right) \\
\vec{y}_{1}=\left(y_{1}(1), y_{1}(2), \cdots, y_{1}(n)\right) \\
\cdots \cdots \\
\vec{y}_{i}=\left(y_{i}(1), y_{i}(2), \cdots, y_{i}(n)\right)
\end{gathered}
$$

where, $\vec{y}_{0}$ and $\vec{y}_{i}$ is respectively as a reference sequence and compared sequence, $n$ is the sequence's length, $i$ is from 1 to $m, m$ is the number of comparative sequence.

\section{2) The Dimensionless of Sequence}

Because the physical significance of the various factors is different in the system, which will is lead to that the original variable sequence is with a different number of dimensions or levels. In order to ensure that all factors have rank and of equal weight, it is needed to be dimensionless. Dimensionless method is commonly used is initial value method and average method. Dimensionless sequence by application initial value and mean value method is expressed as formula (2).

$$
\begin{gathered}
x_{j}(k)=\frac{y_{j}(k)}{y_{j}(1)} \\
x_{j}(k)=\frac{y_{j}(k)}{\frac{1}{n} \sum_{k=1}^{n} y_{j}(k)}
\end{gathered}
$$

where, $j$ is from 0 to $m, k$ is from 1 to $n$.

The new sequence after dimensionless is $x_{0}$ and $x_{1}$.

\section{3) Calculating Correlation Coefficient}

Correlation coefficient is the data points of the $i$-th comparison sequence and reference sequences in the $k$-th degree of correlation, its expression is shown as formula (4). 


$$
\xi_{0 i}(k)=\frac{\Delta_{\min }+\rho \Delta_{\max }}{\Delta_{0 i}(k)+\rho \Delta_{\max }}
$$

The $\Delta_{0 i}(k)$ can be calculated by formula (5).

$$
\Delta_{0 i}(k)=\left|x_{0}(k)-x_{i}(k)\right|
$$

Where, $\xi_{0 i}(k)$ is correlation coefficients, $\Delta_{0 i}(k)$ is the absolute value of the $i$-th comparison sequence and reference sequences in the $k$-th degree of correlation, $\Delta_{\min }$ and $\Delta_{\max }$ is respectively the minimum and maximum absolute difference of each data point, $\rho$ is resolution ratio, $\rho$ is from 0 to 1 , values from 0.1 to 0.5 , usually is 0.5 . Resolution coefficient is increased significance of difference between the correlation coefficient.

\section{4) Calculating Correlation Degree}

Because the number of correlation coefficient is many, the information is too scattered, for ease of compare, to compute an average of correlation coefficient, the correlation degree is the formula (6).

$$
r_{0 i}=\frac{1}{n} \sum_{k=1}^{n} \xi_{0 i}(k)
$$

where, $r_{0 i}$ is correlation degree, the value is from 0 to 1 .

\section{Main Influence Factors of Dividing Coefficient Determined}

In view of the current method of dividing coefficient calculation of many at home and abroad, identify the factors influencing the dividing coefficient values. It is found through analysis that many parameter (impact factor) introduced in dividing coefficient formula, and there is no unified standard. Therefore, in order to better identify and divide the level of effect factors on the effect of dividing coefficient and how dividing coefficient, these influencing factors will be classified, including geological factors 1), controllable factors 2) and integrative factors 3). Geological factors related to the status of the geological features, such as the permeability of layers, connectivity coefficient, the coefficient of interlayer interference, the affect coefficient of sedimentary facieses, the coefficient of permeability anisotropy, perforation thickness, and so on. Controllable factors is the factor that is generated for the operation of people, such as the number of injector and producer, injector producer distance, the measures transformation coefficient, mining width coefficient and the location coefficient. The integrative factors is to consider the performance of the factors of injection wells and the surrounding characteristics of producing wells connected with it, such as the direction formation capacity. These main factors are determined by grey correlation analysis method. Dividing coefficient is established which considers the effect of various factors. Therefore the split result is more realistic.

\section{Gray Correlation Analysis Method to Determine the Main Factors and Weights}

According to the actual water injection profile data of A platform offshore, the 
layer water absorption is chose as the reference sequence. And the effective thickness, permeability, injection-production well spacing, the number of injection-production wells, the direction of formation coefficient are as comparison sequences. Using mean method to dimensionless, resolution ratio is 0.5 , and the correlation degree of various factors is calculated through the formula (6). The values are in Table 1.

According to the correlation degree, the weight values are determined through normalization. It is shown in Table 2.

\section{Single-Layered Water Injection Formula Determined}

The plane dividing coefficient and vertical dividing coefficient are established which taking into account all factors of weight depending on the selected main factors of A platform.

\subsection{Plane Dividing Coefficient}

Plane dividing coefficient to consider the weight of various factors is set up based on the selected five parameters. The formula is formula (7).

$\gamma_{i}=\frac{\sum_{j=1}^{m}\left[\left(K_{i j}+\partial K_{i j}\right)\left(H_{i j}+\partial H_{i j}\right)\left(K H_{i j}+\partial K H_{i j}\right)\left(N_{i j}+\partial N_{i j}\right) / \ln \left(D_{i j}+\partial D_{i j}\right)\right]}{\sum_{i=1}^{n} \sum_{j=1}^{m}\left[\left(K_{i j}+\partial K_{i j}\right)\left(H_{i j}+\partial H_{i j}\right)\left(K H_{i j}+\partial K H_{i j}\right)\left(N_{i j}+\partial N_{i j}\right) / \ln \left(D_{i j}+\partial D_{i j}\right)\right]}(7)$

where, $m, n, I$ respectively is the total number of layer of $i$ water injection well, the total number of injection wells and the number of water injection wells connected with $I$ well.

$K_{i j} H_{i p} K H_{\mathrm{ij}}, N_{i j} D_{i j}$ respectively is the permeability, effective thickness, the direction of formation coefficient, the number of injection-production wells and injection-production well spacing of $j$ of $i$ water injection well.

$\gamma_{i}$ is dividing coefficient of $i$ water injection well, it is dimensionless and existing the formula $(8)$.

$$
\sum_{i=1}^{n} \gamma_{i}=1
$$

$\partial K_{i j}, \partial H_{i j}, \partial K H_{i j}, \partial N_{i j}, \partial D_{i j}$ respectively is the correction of the permeability, effective thickness, the direction of formation coefficient, the number of injection-production wells and injection-production well spacing.

Table 1. The correlation degree of main factors.

\begin{tabular}{cccc}
\hline Classification & The main factors & Sort & Correlation degree \\
\hline II & permeability & 1 & 0.7624 \\
I & effective thickness & 2 & 0.7542 \\
II & injection-production well spacing & 3 & 0.7461 \\
II & the direction of formation coefficient & 4 & 0.7396 \\
II & the number of injection-production wells & 5 & 0.7305 \\
\hline
\end{tabular}


Table 2. The weight of main factors a platform.

\begin{tabular}{cc}
\hline The main factors & Weight values \\
\hline permeability & 0.2042 \\
effective thickness & 0.2020 \\
injection-production well spacing & 0.1999 \\
the direction of formation coefficient & 0.1981 \\
the number of injection-production wells & 0.1957 \\
\hline
\end{tabular}

The correction formula for various weights is formula (9).

$$
\begin{aligned}
& \partial K_{i j}=\left(K_{i j}-\bar{K}\right)\left(w_{K}-\frac{1}{n}\right) \cdot n \\
& \partial H_{i j}=\left(H_{i j}-\bar{H}\right)\left(w_{H}-\frac{1}{n}\right) \cdot n \\
& \partial K H_{i j}=\left(K H_{i j}-\overline{K H}\right)\left(w_{K H}-\frac{1}{n}\right) \cdot n \\
& \partial N_{i j}=\left(N_{i j}-\bar{N}\right)\left(w_{N}-\frac{1}{n}\right) \cdot n \\
& \partial D_{i j}=\left(D_{i j}-\bar{D}\right)\left(w_{D}-\frac{1}{n}\right) \cdot n
\end{aligned}
$$

where $\bar{K}, \bar{H}, \overline{K H}, \bar{N}, \bar{D}$ respectively is the average of the permeability, effective thickness, the direction of formation coefficient, the number of injection-production wells and injection-production well spacing. And $n$ is the number of influencing factors for the construction of dividing coefficient.

$w_{K}, w_{H}, w_{K H}, w_{N}, w_{D}$ respectively is the weight of the permeability, effective thickness, the direction of formation coefficient, the number of injection-production wells and injection-production well spacing after normalization based on the correlation degree value of each parameter.

\subsection{Vertical Dividing Coefficient}

According to the construction process of plane dividing coefficient, vertical dividing coefficient is established in accordance with the A platform water injection wells. The formula is shown as formula (10).

$$
\beta_{i j}=\frac{\left[\left(K_{i j}+\partial K_{i j}\right)\left(H_{i j}+H \alpha_{i j}\right)\left(K H_{i j}+\partial K H_{i j}\right)\left(N_{i j}+\partial N_{i j}\right) / \ln \left(D_{i j}+\partial D_{i j}\right)\right]}{\sum_{j=1}^{m}\left[\left(K_{i j}+\partial K_{i j}\right)\left(H_{i j}+H \alpha_{i j}\right)\left(K H_{i j}+\partial K H_{i j}\right)\left(N_{i j}+\partial N_{i j}\right) / \ln \left(D_{i j}+\partial D_{i j}\right)\right]}
$$

where $\beta_{i j}$ is vertical dividing coefficient of $j$ layer of $i$ water injection well, and it is existed the formula (11).

$$
\sum_{j=1}^{m} \beta_{i j}=1
$$

\subsection{The Formula of Single Well Injection Allocation}

After obtaining the well of plane dividing coefficient, water injection of single 
well injection allocation can be evaluated according to the plane dividing coefficient. The formula is shown as formula (12).

$$
\begin{aligned}
Q_{i w i} & =Q_{i w} \gamma_{i} \\
& =Q_{i w} \frac{\sum_{j=1}^{m}\left[\left(K_{i j}+\partial K_{i j}\right)\left(H_{i j}+\partial H_{i j}\right)\left(K H_{i j}+\partial K H_{i j}\right)\left(N_{i j}+\partial N_{i j}\right) / \ln \left(D_{i j}+\partial D_{i j}\right)\right]}{\sum_{i=1}^{n} \sum_{j=1}^{m}\left[\left(K_{i j}+\partial K_{i j}\right)\left(H_{i j}+\partial H_{i j}\right)\left(K H_{i j}+\partial K H_{i j}\right)\left(N_{i j}+\partial N_{i j}\right) / \ln \left(D_{i j}+\partial D_{i j}\right)\right]}
\end{aligned}
$$

where $Q_{i w i}$ is the number of single monthly injection of Well $i$ injection well, the unit is $10^{4} \mathrm{~m}^{3}$. $Q_{i W}$ is the number monthly injection of total injection wells, the unit is $10^{4} \mathrm{~m}^{3}$.

When injection allocation amount of each injection is determined, divided by total perforation effective thickness of each injection wells and the formula of water intensity of water injection well can be obtained, the formula is formula (13).

$$
Q_{i w H i}=\frac{Q_{i w i}}{30 \times \sum_{k=1}^{m} h_{k}}
$$

where $Q_{i w H i}$ is the strength of well $i$ injection well, the unit is $\mathrm{m}^{3} /(\mathrm{m} \cdot \mathrm{d}), h_{k}$ is effective thickness of $k$ layer of well $I$ injection well, the unit is meter.

\subsection{The Formula of Layer Injection Allocation}

When getting single well injection allocation of water injection wells, the layer injection allocation can be computed according to vertical dividing coefficient, the formula is formula (14).

$$
\begin{aligned}
q_{i w i j} & =Q_{i w i} \beta_{i j} \\
& =Q_{i w i} \frac{\left[\left(K_{i j}+\partial K_{i j}\right)\left(H_{i j}+H \alpha_{i j}\right)\left(K H_{i j}+\partial K H_{i j}\right)\left(N_{i j}+\partial N_{i j}\right) / \ln \left(D_{i j}+\partial D_{i j}\right)\right]}{\sum_{j=1}^{m}\left[\left(K_{i j}+\partial K_{i j}\right)\left(H_{i j}+H \alpha_{i j}\right)\left(K H_{i j}+\partial K H_{i j}\right)\left(N_{i j}+\partial N_{i j}\right) / \ln \left(D_{i j}+\partial D_{i j}\right)\right]}
\end{aligned}
$$

where $q_{\text {iwij }}$ is injection monthly volume of $j$ layer of $i$ injection well, the unit is $10^{4}$ $\mathrm{m}^{3}$.

\subsection{The Formula of Conventional Injection}

At present the conventional application water injection dividing coefficient is formation coefficient method, the computational formula is that

$$
\lambda_{i j}=\frac{k h_{i j}}{\sum_{j=1}^{m} k h_{i j}}
$$

where $\lambda_{i j}$ is dividing coefficient of $j$ layer of $i$ water injection well, $\lambda_{i j}$ is formation coefficient of $j$ layer of $i$ water injection well. 
According to formula (15), for the better reservoir physical property is the more water quantity, the poorer reservoir property is the less water quantity. This method does not take into account the surrounding the well connectivity, there is certain limitation.

\section{The Analysis of the Field Test Result}

According to the formula determined by multi-factor dividing coefficient, the four wells are layer water injection allocation for a platform of bohai oilfield, at the same time the calculation of one well is compared with the conventional injection formula result; the result is shown in Table 3.

A platform of Bohai oilfield is implemented stratified water injection since 2010, before 2013 it is injected by conventional injection formula, after the June of 2013 is injected by multi-factor dividing coefficient injection formula. Through the adjustment of the water injection, A platform development effect is improved obviously through analyzing the change of oil production and water cut of a platform. Figure 1, Figure 2 respectively are the curve of water cut, oil production and natural decline rate for A platform water flooding development in 2013. Through the application of the formula (14) in this article, after stratified water injection allocation a platform oil production is increased $2.56 \times 10^{4}$ $\mathrm{m}^{3} / \mathrm{d}$, water cut is reduced by $6.1 \%$, the natural decline rate is reduced by $0.9 \%$.

As shown in Figure 1 and Figure 2, after dividing coefficient determined by application of multi-factor small layer of water distribution, from July 2013, the water cut of platform A reduces the production increase. By Comparison two different water injection methods in Table 3, water injection rate determined by conventional methods consider only a small layer of reservoir properties, when the number of well layers in the communication is not the same, the method determines the amount of water is difficult to meet the actual production. Water injection in considering the application of this article to determine reservoir properties at the same time taking into account the surrounding wells connected to calculate the amount of water needed is more in line with actual production. By comparison the layer water, a small number of wells layer connectivity more appropriate allocation of more water to reach the small layer of balanced

Table 3. The result of different water injection formula.

\begin{tabular}{ccccccc}
\hline Well & Layer & $\begin{array}{c}\text { Thickness } \\
(\mathrm{m})\end{array}$ & $\begin{array}{c}\text { Permeability } \\
(\mathrm{Md})\end{array}$ & $\begin{array}{c}\text { The number } \\
\text { of well }\end{array}$ & $\begin{array}{c}\text { Conventional } \\
\text { formula } \\
\mathrm{Q}_{1}\left(\mathrm{~m}^{3} / \mathrm{d}\right)\end{array}$ & $\begin{array}{c}\text { The article formula } \\
\mathrm{Q}_{2}\left(\mathrm{~m}^{3} / \mathrm{d}\right)\end{array}$ \\
\hline & $\mathrm{N}-1$ & 4.3 & 883 & 3 & 55 & 125 \\
& $\mathrm{~N}-2$ & 8.6 & 966 & 1 & 120 & 65 \\
$\mathrm{~A} 1$ & $\mathrm{~N}-3$ & 6.4 & 659 & 2 & 61 & 88 \\
& $\mathrm{~N}-4$ & 9.2 & 1148 & 2 & 153 & 105 \\
& & & & & \\
& $\mathrm{~N}-5$ & 1057 & 1 & 61 & 67 \\
\hline
\end{tabular}




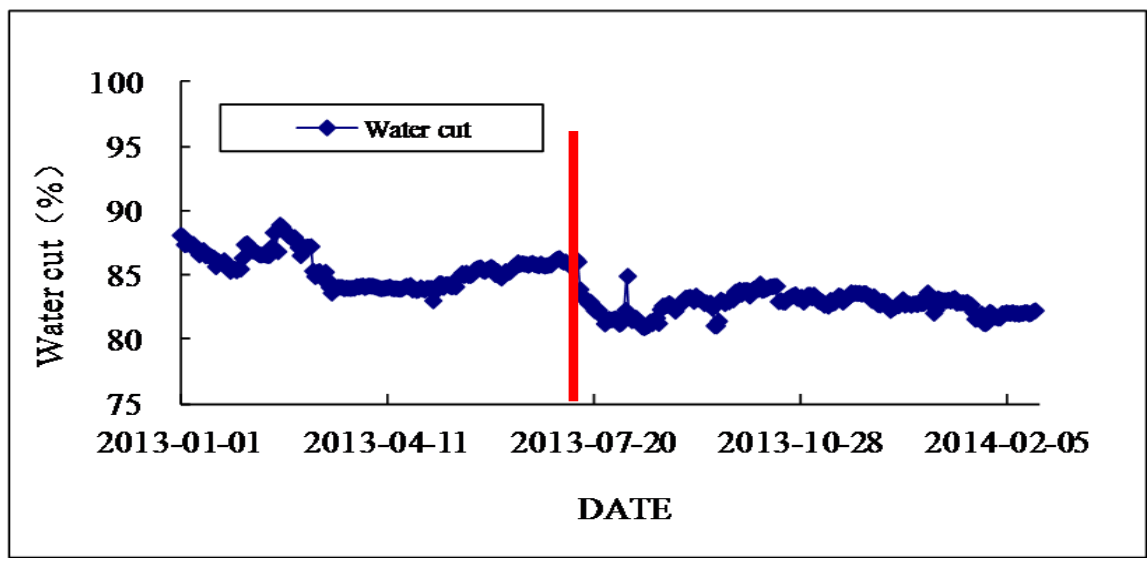

Figure 1. The curve of water cut a platform.

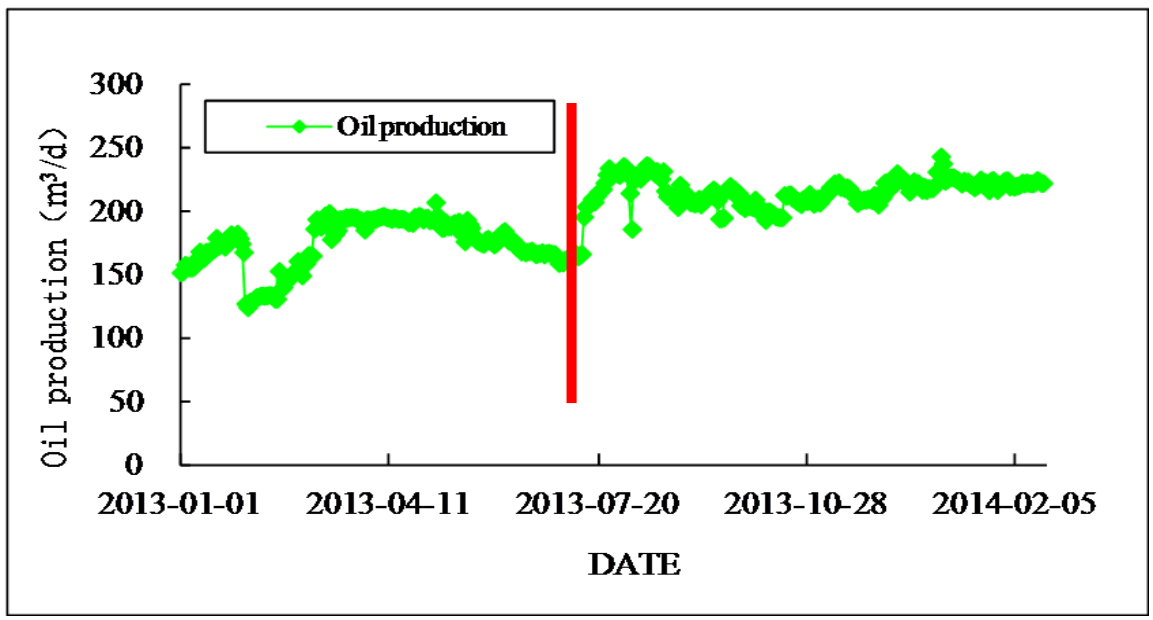

Figure 2. The curve of oil production a platform.

injection. At the same time we can see the amount of water applied two methods of N-3 and N-5 layer layers or less, indicating that the number of connected wells in the small layer is insignificant, water control multiple factors identified herein formula can be simplified to a conventional injection water formula applications.

\section{Conclusions}

1) Based on marine geology and development situation of platform A, influencing factors of water injection dividing factor have been analyzed. By gray correlation analysis method, the main factors are permeability, formation factor of effective thickness direction, the number of injection, production wells and injection wells, and the weight of each factor in the value of the share rights dividing coefficients is determined.

2) Based on the main factors and weight values, water injection formula of platform $\mathrm{A}$ is established, and with the contrast of conventional water injection formula, the difference reason between the different formulas has been analyzed. 
3) Through the new water injection formula, water injection wells on the platform A have been adjusted, and the development effect has been improved.

4) The study to determine the sea water flooding and the reservoir with water stratification has some practical value and significance.

\section{Conflicts of Interest}

The authors declare no conflicts of interest regarding the publication of this paper.

\section{References}

[1] Xiong, X.D., Yang, J.J. and Liu, K. (2004) Determination of Water Injection Rate for Single Injection Well Employing Dividing Coefficient Approach. Fault-Block Oil \& Gas Field, 11, 56-61.

[2] Sun, P.X. (2014) Analysis and Application of Gray Correlation Method. Mathematics in Practice and Theory, 44, 97-101.

[3] Yan, C.H. and Chen, Q. (2007) Application of Injection Well Contrasting Test in Injection Project Adjustment. Drilling \& Production Technology, 31, 71-75.

[4] Li, F.Q., Liu, L.Q. and Ding, J.S. (2005) A Study on Calculation of Accumulative Water in Taken Rate of Separate Layer. Henan Petroleum, 19, 28-32.

[5] Jia, X.F., Li, Q.Z. and Yang, J. (2012) A Method to Allocate Injection Volume for Separate Layers in a Water-Injection Well Based on the Remaining Oil Distribution. China Offshore Oil and Gas, 24, 38-40.

[6] Jia, X.F., Ma, K.Q. and Li, Y.P. (2012) Injection Allocation Determination Method for Separate Injection Well Based on Remaining Oil Distribution. Petroleum Drilling Techniques, 40, 72-76.

[7] Ma, X.B., Zhou, W. and Qian, C.H. (2013) Optimizing Hydraulic Fracturing Wells with the Methods of FAHP and Grey Relational Analysis. Computing Techniques for Geophysical and Geochemical Exploration, 35, 369-372.

[8] Yin, H.J., Zhang, J.T., Zhang, H.H., et al. (2012) Appling Grey Correlation Analysis Method to Determine the Separated Layer Water Injection. Mathematics in Practice and Theory, 42, 94-99.

[9] Mao, D.F., Duan, M.L., Li, X.Z., et al. (2013) Selection of Deepwater Floating Oil Platform Based on Grey Correlation. Petroleum Exploration and Development, 40, 743-746. https://doi.org/10.1016/S1876-3804(13)60107-X

[10] Zhao, J. (2007) Take Weights of Land Evaluation Model Based on Grey Correlation Degree. Pioneering with Science \& Technology Monthly, No.8, 46-47.

[11] Lian, C.B., Zhong, J.H. and Cai, F.L. (2006) Influencing Factors Analysis of Oil Field Output Based on Grey Correlation Analytical Method. Natural Gas Geoscience, 17, 851-853.

[12] Li, Y.W., Ai, C., Hu, C.Y., et al. (2014) Evaluating Multistage Fracturing Effect of Horizontal Wells Using Fuzzy Comprehensive Evaluation and Grey Relational Grade Analysis. Mathematics in Practice and Theory, 44, 51-56.

[13] Ye, X.C. (2011) The Application of Grey Relationship System at Later Period of Polymer Drive in Oilfield Development. Science Technology and Engineering, No. 25, 6178-6180.

[14] Tian, F., Li, A., Chen, D.C., Li, H. (2012) The Model Research and Software Devel- 
opment of Gray Correlation Degree and Multiple Quadratic Regression Analysis. Inner Mongolia Petrochemical Industry, No. 9, 118-120.

[15] Xie, R.C., Zhou, W., Gao, Y.Q., et al. (2008) Application of Partial and Grey Correlation Methods to Layer Selection for Fracturing in Tight Sand Gas Reservoirs. Oil \& Gas Geology, 29, 797-800.

[16] Chen, S.-S., Deng, H.-C., Wu, Q.-Y., et al. (2012) Application of Gray Associative Analysis in the Research on Influence Factors of the Fracturing Effect. Liaoning Chemical Industry, 41, 829-831.

[17] Fang, Q., Zhang, Y.-Y., Sun, X.-F., et al. (2012) Remaining Oil Distribution in Low-Permeability Reservoir by Permeability-Saturation Curve Method and Gray Correlation Method. Journal of Chengde Petroleum College, 14, 20-25.

[18] Jiao, H.Y. (2014) Optimal Design Research to Fracture Parameters of Horizontal Well Fracturing. Journal of Petrochemical Universities, No. 1, 35-41.

[19] Hu, Q.H. (2016) Influential Factors and Grey Correlation Analysis of Horizontal Well Development in G Oilfield in South Sudan. Journal of Chongqing University of Science and Technology (Natural Sciences Edition), 18, 4-7. 